\title{
The Seasonal-scale Persistence of Tropical Tropospheric Temperature Associated with the El Niño/Southern Oscillation
}

\author{
Takuji KUBOTA \\ Division of Earth and Planetary Science, Graduate School of Science, Kyoto University, Kyoto, Japan \\ and \\ Toru TERAO \\ Faculty of Informatics, Osaka Gakuin University, Osaka, Japan
}

(Manuscript received 10 September 2001, in revised form 3 March 2003)

\begin{abstract}
From an examination of the analyses of the NCEP/NCAR reanalysis data for the years 1979 to 2000 , it is found that the persistence of tropical $200 \mathrm{hPa}$ geopotential heights, representing tropospheric mean temperatures, exhibits a 'barrier' during the boreal autumn, especially between September and October. On the other hand, the persistence of indices associated with the El Niño/Southern Oscillation (ENSO), which is intimately related to variations of the tropical tropospheric mean temperature, have been shown to decrease during the spring.

From this feature, a tropical climatic year that starts in October is proposed. The 'annual' average of the tropical zonal mean $200 \mathrm{hPa}$ heights for the tropical climatic year introduced above is presently defined as the tropical year index (TYI).

Associated with the TYI, a zonally uniform tropical temperature anomaly is prominent at the 700$150 \mathrm{hPa}$ levels over the period from November to the following September. On the other hand, the tropical temperatures at the $1000-850 \mathrm{hPa}$ levels are not zonally uniform, but vary almost simultaneously with the underlying tropical sea surface temperatures. The temperature anomalies are found to be larger in the upper troposphere $(0.4-0.6 \mathrm{~K})$, than in the lower troposphere $(0.2-0.3 \mathrm{~K})$.

The tropical tropospheric warming (or cooling) is not directly connected with the increase (or decrease) in the amount of the precipitation over the entire tropics. The mean mass of tropical water vapor, within the 700-300 hPa levels, gradually increases after the peak of ENSO events, unlike the tropospheric temperatures.
\end{abstract}

\section{Introduction}

Recently, extensive studies have been conducted on the global warming of the surface air temperature (e.g., Houghton et al. 2001). From

Corresponding author: Takuji Kubota, Division of Earth and Planetary Science, Graduate School of Science, Kyoto University, Kyoto, 606-8502, Japan.

E-mail: kubota@dpac.dpri.kyoto-u.ac.jp

(C) 2003, Meteorological Society of Japan the view of global climate detection, there has been increasing interest in the long-term trend of the tropospheric temperature. Chelliah and Ropelewski (2000), however, pointed out that, in addition to the serious biases among datasets, the interannual variability of tropospheric temperatures profoundly influences all estimates of tropospheric temperature trends. In fact, variations associated with the El Niño/ Southern Oscillation (ENSO) on 2 to 7 year time scales are clearly seen in the time series of 
tropospheric temperature throughout the tropics. It has been shown that a high positive correlation exists between the tropical tropospheric mean temperature, and the sea surface temperature (SST) in the equatorial eastern Pacific during the boreal winter (Horel and Wallace 1981).

Furthermore, using radiosonde data, several studies have revealed that the tropical tropospheric mean temperature lags, by three to six months, behind the SST of the equatorial eastern Pacific (Newell and Weare 1976; Angell 1981; Pan and Oort 1983). Using data from the tropospheric channel of microwave sounding units, which provide a measure of tropospheric mean temperatures, Yulaeva and Wallace (1994) confirmed a 3-month phase lag between the ENSO time series and that of the tropical tropospheric mean temperature. However, radiosonde stations are sparsely placed in the tropics, so that spatial patterns can not be fully realized. Yulaeva and Wallace (1994) utilized satellite data to obtain information with a precise horizontal resolution. On the other hand, due to the coarse vertical resolution of satellite soundings, vertical differences in tropospheric temperatures could not be obtained. Thus, an examination of a more detailed spatial structure is required to determine the cause of the above mentioned lag.

In previous studies, the above feature was calculated as the maximum of the simply lagged correlation between the monthly time series of both variables. In order to gain new insight, it might be more important to discuss the relationship with respect to the seasonal march. Using the datasets of the SST, the sea level pressure, and the Southern Oscillation Index, many ENSO events have been shown to be phase locked to the annual cycle (Rasmusson and Carpenter 1982; Wright 1985; Trenberth and Shea 1987; Webster and Yang 1992). It has been proposed that a 'persistence barrier', or 'predictability barrier' exists during the boreal spring, as found in data analyses and model calculations of the ENSO. The composite of 10 ENSO events for the period 1946-1993 demonstrated that SST anomalies over the equatorial eastern Pacific increased for the months between August and the following January, and then rapidly decayed in January and February (Harrison and Larkin 1998). This evolution pattern of the SST anomalies may have an influence on the evolution of tropical tropospheric temperature anomalies.

In the context of a significant coupling of the ENSO to the Asian summer monsoon (e.g., Webster et al. 1998), Yasunari (1991) proposed the concept of a 'monsoon year'. This was based on the hypothesis that the monsoon heating may be an important factor in a coupled oceanatmosphere system. The starting point of this cycle was just before the onset of the northern summer monsoon. As discussed above, the tropical tropospheric temperature tends to lag several months behind the ENSO phase, which implies that the tropical tropospheric temperature can retain information beyond the end of the monsoon year.

The variations of tropical tropospheric temperatures can be related to those of precipitation and water vapor. In the tropics, the release of latent heat is an important factor in the thermal balance of the atmosphere (Peixoto and Oort 1992). It is essential to examine variations of precipitation that are closely connected to the release of latent heat. It has been well known that warming will lead to an increase in atmospheric water vapor on the assumption that relative humidity remains constant due to the Clausius-Clapeyron equation. In addition, this increase will lead to a further warming, as water vapor is a greenhouse gas (e.g., Blankenship and Wilheit 2001). In fact, Sun and Oort (1995), using radiosonde data, demonstrated the vertical structure of the positive correlation between variations of the tropical mean specific humidity and the tropical mean temperature at the same level. Thus, an examination of the variations of precipitation and water vapor may possibly lead to an explanation of the lag between the tropospheric temperature and ENSO events.

The data presently analyzed are from the period 1979 through 2000, while the NCEP/ NCAR reanalysis data are available from 1949. This can be justified for two reasons. One, satellite sounding data have been used to derive vertical profiles of temperature since November 1978 (Kalnay et al. 1996; Basist and Chelliah 1997). As noted above, there are only sparsely placed radiosonde stations in the tropics. The quality of reanalysis data may depend upon the additional use of satellite data. 
The other reason is that previous reports have pointed out variations on interdecadal time scales, which are beyond the scope of the present paper. A "climate shift" that occurred in the mid-1970s, was found in the time series of tropical Pacific SSTs (Nitta and Yamada 1989; Trenberth 1990), and tropical surface air temperatures in the NCEP/NCAR reanalysis data (Chelliah and Ropelewski 2000). Therefore, use is made of only data after 1979 for analysis in the present paper. Differences between before and after the climate shift will be discussed in a future study.

The major points of the present paper are summarized as follows: (1) The persistence of both the tropical tropospheric temperature and the tropical SST are documented with special attention to the seasonal march. This point is strongly associated with research to determine the signals that convey the information of ENSO activities to the succeeding summer, i.e., beyond the spring persistence barrier. (2) Spatial, in particular, the vertical differences in the persistence of tropical temperatures are discussed in detail, making use of the reanalysis data. These details are also expected to be useful in forthcoming research that intends to distinguish the longer-term trend of tropospheric temperature from the variations associated with ENSO.

Datasets are briefly documented in Section 2 . Section 3 demonstrates the correlation between the tropical tropospheric temperature and ENSO. The persistence of the tropical tropospheric mean temperature is examined and compared with persistence of ENSO events. In Section 4, the spatial and temporal structure of the persistence of the tropical tropospheric temperature is tested with a presently defined index.

Section 5 describes the differences in tropical temperature variations found in the planetary boundary layer and the free troposphere. Section 6 focuses on the water vapor and precipitation variations, which may be closely connected to the seasonal-scale persistence of the tropical temperature. Conclusions are given in Section 7.

\section{Data and methods}

The datasets used in the present study are the monthly averaged National Centers for En- vironmental Prediction (NCEP)/National Center for Atmospheric Research (NCAR) reanalysis (Kalnay et al. 1996), the United Kingdom Meteorological Office Global sea Ice coverage and Sea Surface Temperature (UKMO GISST) Version 2.3b (Hurrell and Trenberth 1999), and the CPC Merged Analysis of Precipitation (CMAP) (Xie and Arkin 1997) from January 1979 through December 2000. The CMAP dataset is based on gauge observations, satellite estimates, and numerical model outputs. The NCEP/NCAR reanalysis data are given on seventeen pressure levels (1000, 925, 850, 700, $600,500,400,300,250,200,150,100,70,50$, $30,20,10 \mathrm{hPa}$ ), except for specific humidity at the eight levels at and below $300 \mathrm{hPa}$. In the present paper, $200 \mathrm{hPa}$ geopotential heights are used as the index of the tropospheric mean temperature, according to the hydrostatic equation, which will be verified in Section 4 .

Trenberth and Guillemot (1998) pointed out that the reanalysis moisture fields contain large and significant biases in the tropics, and specific humidities should be treated with caution. Here, values averaged over large areas are taken into account, and the variations on small horizontal scales are disregarded in the analyses of the humidity.

The significance of the correlation coefficients were examined by null hypothesis testing (von Storch and Zwiers 1999), on the assumption that year-to-year variations of any parameter can be regarded as sequences of statistically independent events. This assumption can be invalid if the time series have any highly prominent variabilities, such as the tropospheric biennial oscillation (Yasunari and Seki 1992), or interdecadal variabilities. However, this is not the case in the present analysis, as will be shown in the next section.

\section{Seasonal-scale persistence of the tropical tropospheric temperature}

\subsection{The autumn persistence barrier}

In this subsection, the autumn persistence barrier of the tropical tropospheric mean temperature is suggested, according to features found in the correlation between months by values of tropical tropospheric mean temperatures. The time series of the monthly persistence $P_{m}(k)$ is defined as the correlation between the two sets of months; that is, months 

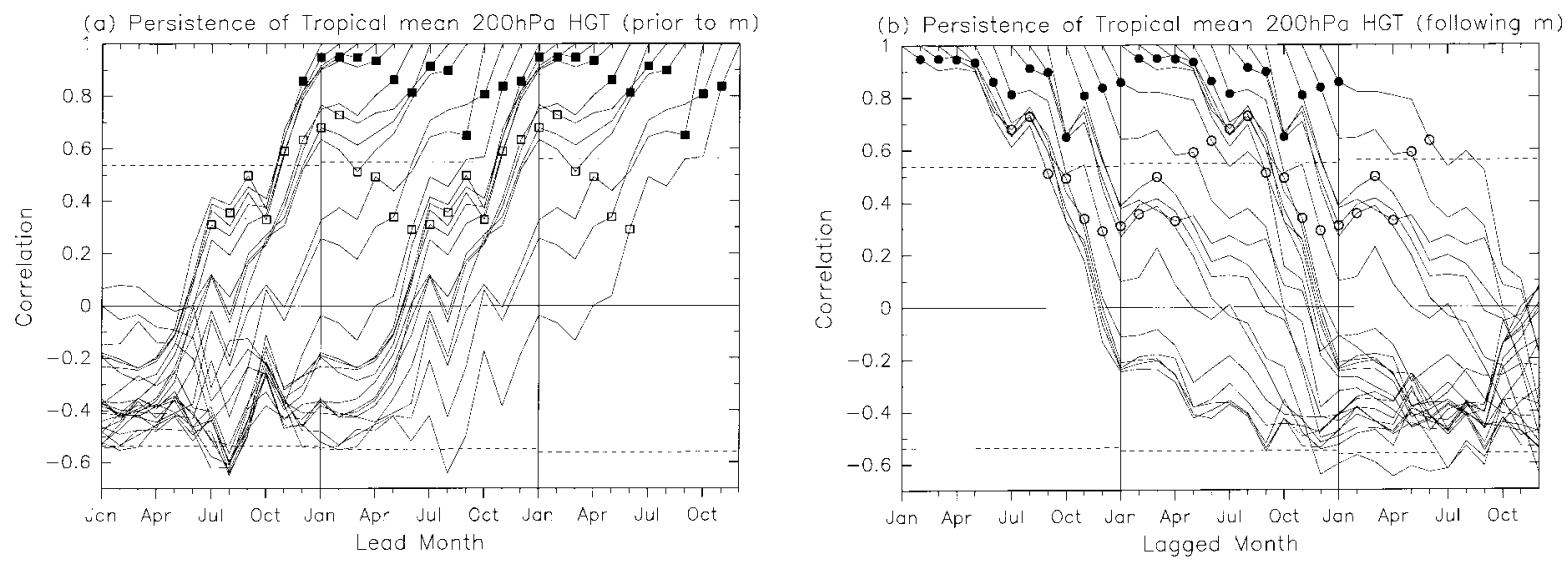

Fig. 1. Persistence of the tropical mean $200 \mathrm{hPa}$ height $P_{m}(k)$ (see text for details). Each curve describes correlation coefficients between the time series of the reference month $m$ and (a) the lead month prior to $m$, or (b) the lagged month following $m$. The heights were averaged zonally between $15^{\circ} \mathrm{S}$ and $15^{\circ} \mathrm{N}$. The solid circles and open circles denote the $P_{m}(1)$ and $P_{m}(6)$, respectively. The solid squares and open squares denote the $P_{m}(-1)$ and $P_{m}(-6)$, respectively. Dashed horizontal lines indicate the $1 \%$ significance level.

$m$ and months $m+k$, where $k$ is the lag (Torrence and Webster 1998).

Figures $1 \mathrm{a}$ and $\mathrm{b}$ show the persistence of the tropical mean $200 \mathrm{hPa}$ geopotential height. Numerous lines of $P_{m}(k)$ are included in these figures. These lines represent the correlation coefficients of geopotential height $z$ between a selected month, $m$ and the lead month $m-k$. For example, the line at the left end of the left panel (Fig. 1a) is the correlation coefficient between $z(\operatorname{Jan})$ and $z(\operatorname{Jan}-k)$, where $m$ in this case is January. The solid square on this line is the correlation coefficient between $z($ Jan $)$ and $z(\operatorname{Dec}(-1))$, where $(-1)$ denotes the previous year. The target variable of $z$ is a one-month difference. Similarly, the open square on the same line of Fig. 1a is the correlation coefficient between $z(\operatorname{Jan})$ and $z(\operatorname{Jun}(-1))$. The target variable $z$ is now a six-month difference.

In summary, Fig. 1a shows the lead correlation, in which the month of the target variable is earlier than the month of the host variable. On the other hand, Fig. 1b is the lagged correlation coefficient in which the target variable month is later than the month of the host variable.

In the left panel (Fig. 1a), one clear result is that the black squares drop off substantially, first in June and secondly in October, with the October drop being greater than the June drop.
In the right panel (Fig. 1b), the black circles drop off substantially, first in May and again in September. The minimum of $P_{m}(1)$ (the black circle) is a combination of September and October. The open circles, and the open squares, indicate the $P_{m}(6)$ and $P_{m}(-6)$, respectively. The values of $P_{m}(6)$ that are greater than the $1 \%$ significance level are combinations of November-May, December-June, JanuaryJuly, and February-August. None of the pairs span either the months of September or October.

Figures 2 are the same as Figs. 1, except for SSTs averaged over the NINO3 area (defined as $\left.5^{\circ} \mathrm{S}-5^{\circ} \mathrm{N}, 150^{\circ}-90^{\circ} \mathrm{W}\right)$. These values are taken as indices of ENSO events. Regardless of the reference month, the persistence of the NINO3 SST correlations is consistently high until March, when it then exhibits a rapid decline during the boreal spring, as pointed out in Torrence and Webster (1998). The minimum of $P_{m}(1)$ shown in Fig. $2 \mathrm{~b}$ is a combination of May and June.

From the results in Figs. 1 and 2, a 4-month lag can be seen between the spring persistence barrier of the NINO3 SSTs, and the autumn persistence barrier of the tropical $200 \mathrm{hPa}$ heights in terms of the $P_{m}(1)$ values.

The lagged correlations between the yearto-year variations of the tropical tropospheric 

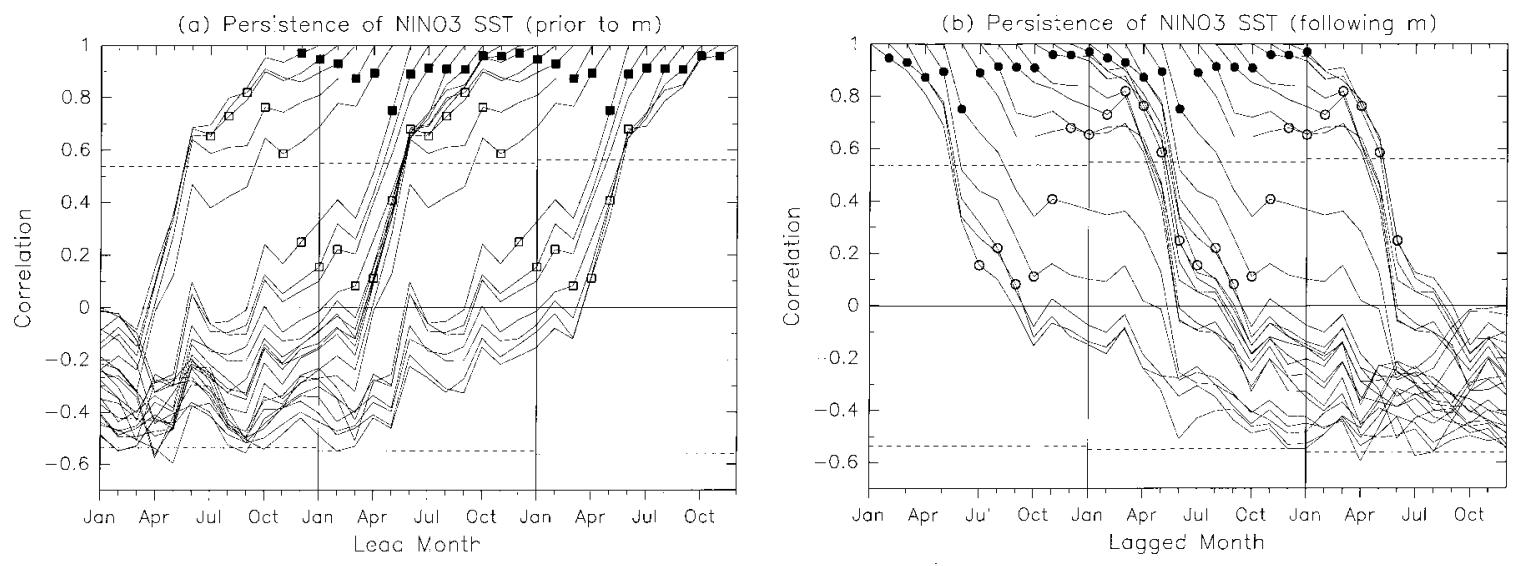

Fig. 2. The same as in Fig. 1, except for the NINO3 SST.

temperatures, and the NINO3 SSTs for each month are calculated and displayed in Fig. 3. The geopotential heights were averaged over the tropics between $15^{\circ} \mathrm{S}$ and $15^{\circ} \mathrm{N}$. The horizontal and vertical axes denote the months of the datasets used in the calculation of the correlations. The former axis is for the NINO3 SSTs and the latter for tropical tropospheric temperatures. The values of $Y(0)$ signify the months of the reference year, while those of $Y(-1)$ denote the year prior to and $Y(+1)$ the year after $Y(0)$. The thick solid line plotted in the figure indicates the simultaneous correlations.

The most prominent feature seen in this figure is the rectangular area of significant positive correlations, indicating that intimate relationships between these two variables are restricted to specific periods. The two variables are highly correlated when the months of the NINO3 SSTs, and the tropical mean $200 \mathrm{hPa}$ heights, are between July in $Y(-1)[\operatorname{July}(-1)]$ and April in $Y(0)$ [April(0)], and between November $(-1)$ and August $(0)$, respectively. In other words, when the month of the tropical mean heights is fixed, the correlation coefficients are above the $1 \%$ significance level for the months between July and the following April. During this period, the values vary more widely during the boreal spring (April to June) than in the other seasons. This feature corresponds to the spring persistence barrier of ENSO indices. On the other hand, when the month of the NINO3 SST is fixed, the correlation coefficients are above the $1 \%$ significance level for the period between November and the following August. Here, the values vary more widely during the boreal autumn than in the other seasons.

The second prominent feature in Fig. 3 is that the center of the high correlation is not located symmetrically around the diagonal line, but it is shifted left by 4 months. This indicates that the index of the NINO3 SST proceeds the index of the tropical mean $200 \mathrm{hPa}$ height by 4 months. This fact may suggest that the NINO3 SST is the cause for these time variations, and that the tropical mean $200 \mathrm{hPa}$ height is the consequence of ENSO events. The third feature is that the spring barrier can be found during April in the NINO3 SSTs (see Fig. 2b), while the autumn barrier is found during September in the tropical mean $200 \mathrm{hPa}$ heights (see Fig. 1b).

\subsection{Definition of the Tropical Year Index (TYI)}

In the previous subsection, a "persistence barrier" was found in the tropical tropospheric mean temperature during the boreal autumn. This result demonstrates that it is not appropriate to examine the year-to-year variation of tropical tropospheric temperatures using annual mean values that are calculated for the calendar year (the cycle of a year starting with January). Therefore, the Tropical Year Index (TYI) is proposed. This is defined as the mean tropical $200 \mathrm{hPa}$ height, averaged over the period between October of the previous year and September of the reference year. The averaging 


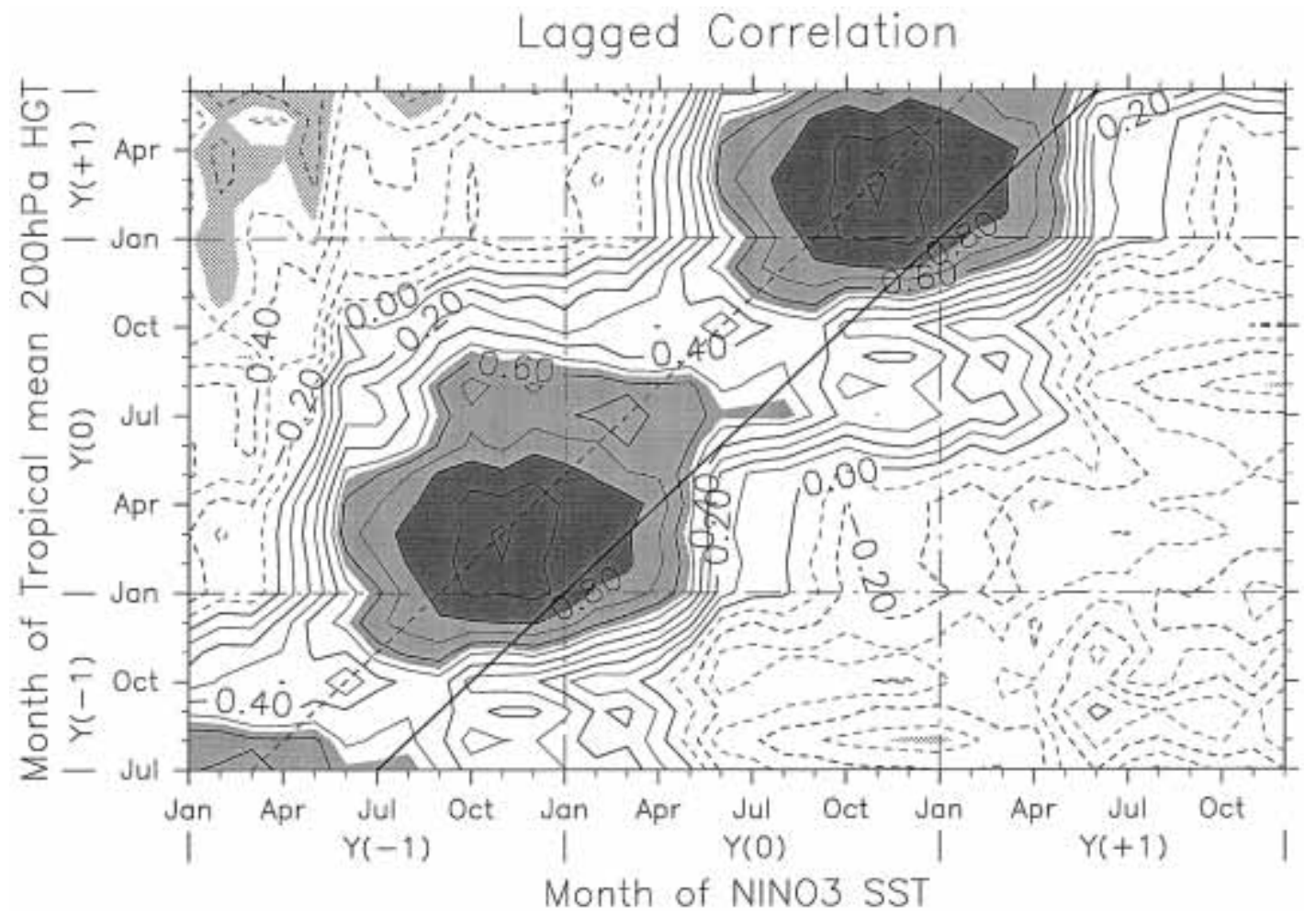

Fig. 3. Lagged correlations between the tropical mean $200 \mathrm{hPa}$ height and the NINO3 SST. The heights were averaged zonally between $15^{\circ} \mathrm{S}$ and $15^{\circ} \mathrm{N}$. The horizontal and vertical axes indicate the months of the NINO3 SST and those of the height, respectively. The $Y(0)$ values denote the months of the reference year, while those of $Y(-1)$ and $Y(+1)$ denote the year prior to and after $Y(0)$, respectively. The thick solid line indicates the same month, while the broken line parallel to the solid line denotes a 4 month shift. The contour interval is 0.1 . Correlation coefficients greater than 0.55 (the $1 \%$ significance level) are indicated by shading, and less than -0.55 by stippling. Coefficient values greater than 0.8 are emphasized by the darker shading.

period is determined from the fact that the minimum $P_{m}(1)$ of the tropical $200 \mathrm{hPa}$ height is found for $m=$ September (Fig. 1).

\subsection{Temporal evolution}

It is a fundamental part of this study to examine the temporal evolution of the tropical tropospheric temperature, and the equatorial eastern Pacific SST. In Fig. 4, lagged correlation coefficients between the TYI (as defined above), and the target variables are shown by the lines, while the bars indicate anomalies regressed upon the TYI. The target variables are the NINO3 SSTs (open circles, open bars), and the tropical $\left(15^{\circ} \mathrm{S}-15^{\circ} \mathrm{N}\right)$ zonal mean $200 \mathrm{hPa}$ heights (solid circles, stippled bars). The correlation coefficients between the TYI and the NINO3 SST, and those between the TYI and the tropical tropospheric temperature exceed the $1 \%$ significance level (dashed horizontal lines) during the period between $\operatorname{July}(-1)$ and April(0), and between November $(-1)$ and September(0), respectively. This result indicates that anomalies of the NINO3 SST and the tropical tropospheric mean temperature tend to persist from $\operatorname{July}(-1)$ to $\operatorname{April}(0)$ and from November $(-1)$ to September $(0)$, respectively. A simultaneous close relationship exists during the period between November $(-1)$ and $\operatorname{April}(0)$.

Discussion is now focused on the regression coefficients when the correlations are greater than the $1 \%$ significance level. The NINO3 SST anomalies and the $200 \mathrm{hPa}$ height anomalies increase during the period between $\operatorname{July}(-1)$ $[0.51 \mathrm{~K}]$ and December $(-1)[1.1 \mathrm{~K}]$, and be- 


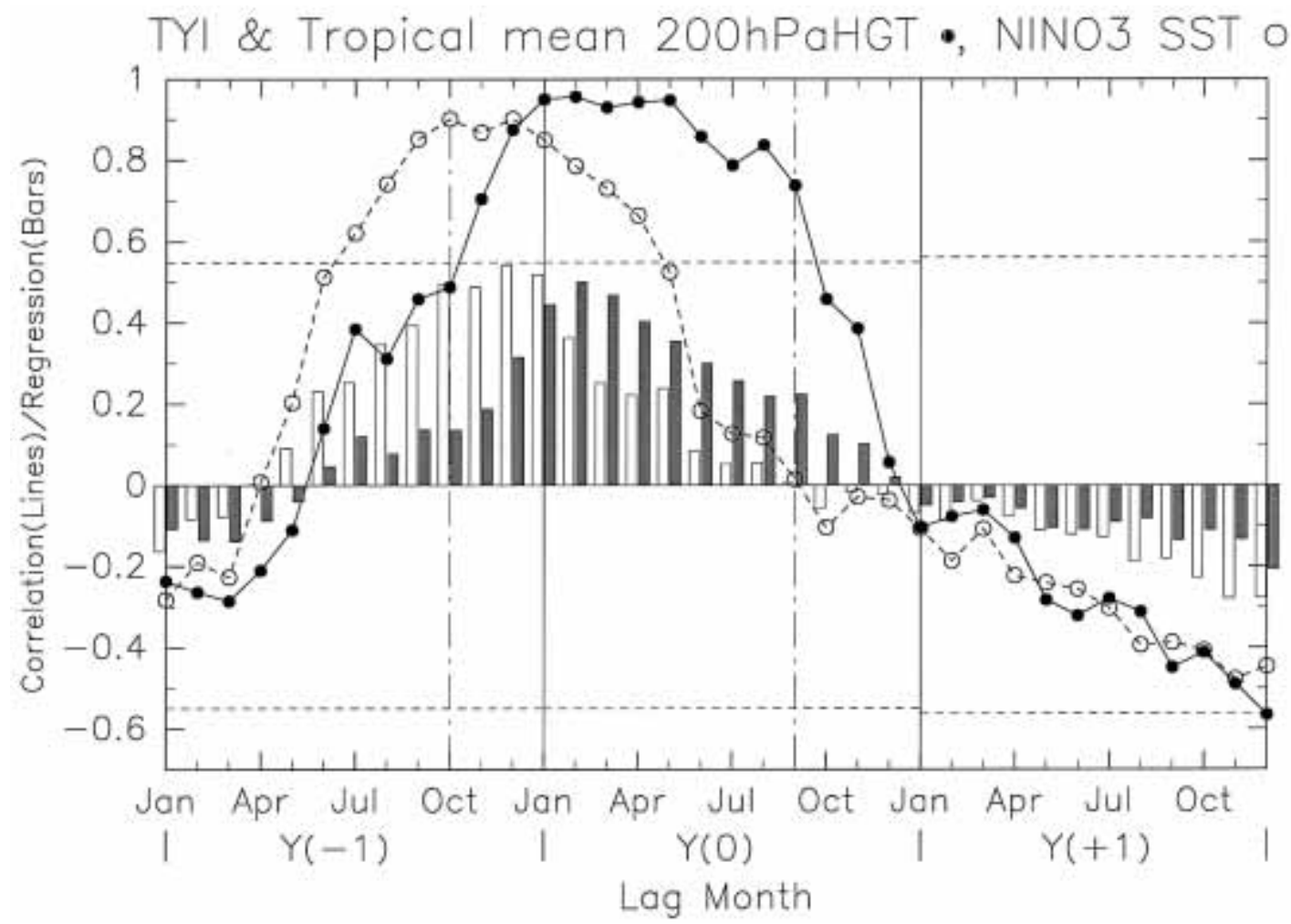

Fig. 4. Lagged correlation coefficients between the TYI (the reference variable) and the target variables indicated by the lines. The bars indicate anomalies regressed upon the TYI. The target variables are the NINO3 SSTs (open circles, open bars) and the tropical $\left(15^{\circ} \mathrm{S}-15^{\circ} \mathrm{N}\right)$ zonal mean $200 \mathrm{hPa}$ heights (solid circles, hatched bars). The horizontal axes denote the months of the target variables. Horizontal dashed lines indicate the $1 \%$ significance level. Vertical dash-dotted lines indicate the averaging period of the TYI. Values of the anomalies in the figure were multiplied by a factor of 0.5 [NINO3, SST(K)] or 0.02 [200 hPa, HGT(m)].

tween November $(-1)[9.4 \mathrm{~m}]$ and $\operatorname{February}(0)$ $[25.0 \mathrm{~m}]$, respectively; and then decrease during the period between December $(-1)$ and $\operatorname{April}(0)[0.45 \mathrm{~K}]$, and between February(0) and September $(0)$ [11.2 m], respectively. Interestingly, the tropospheric temperature anomalies rise quickly and fall slowly, while the SST anomalies rise slowly and fall quickly. This result does not indicate that the variations of the tropical temperature associated with the TYI are simply lagged behind those of the tropical eastern Pacific SST.

\section{Spatial and temporal structure of the persistence}

\subsection{Horizontal patterns}

In this subsection, patterns of persistence in the tropical tropospheric temperature and tropical SST are statistically examined with respect to the TYI.

Figures 5a and b show horizontal structures of tropospheric temperature variations regressed on the TYI, before and after the spring persistence barrier of the ENSO, respectively. In Fig. 5a, the correlation coefficients exceed the $1 \%$ significance level (shading) over the tropics between $20^{\circ} \mathrm{S}$ and $20^{\circ} \mathrm{N}$. This pattern of correlation coefficients is similar to that found in Newell and Wu (1992), as derived from satellite data. The $200 \mathrm{hPa}$ height anomalies regressed on the TYI, are all above $15 \mathrm{~m}$ in the tropics as shown in Fig. 5a. A wave pattern similar to the theoretical solutions of Gill (1980) can be seen around $15^{\circ} \mathrm{S}$ and $15^{\circ} \mathrm{N}$ in the tropical central Pacific $\left(90^{\circ} \mathrm{W}\right.$ to $\left.160^{\circ} \mathrm{W}\right)$, which has been pointed out in previous papers, such 


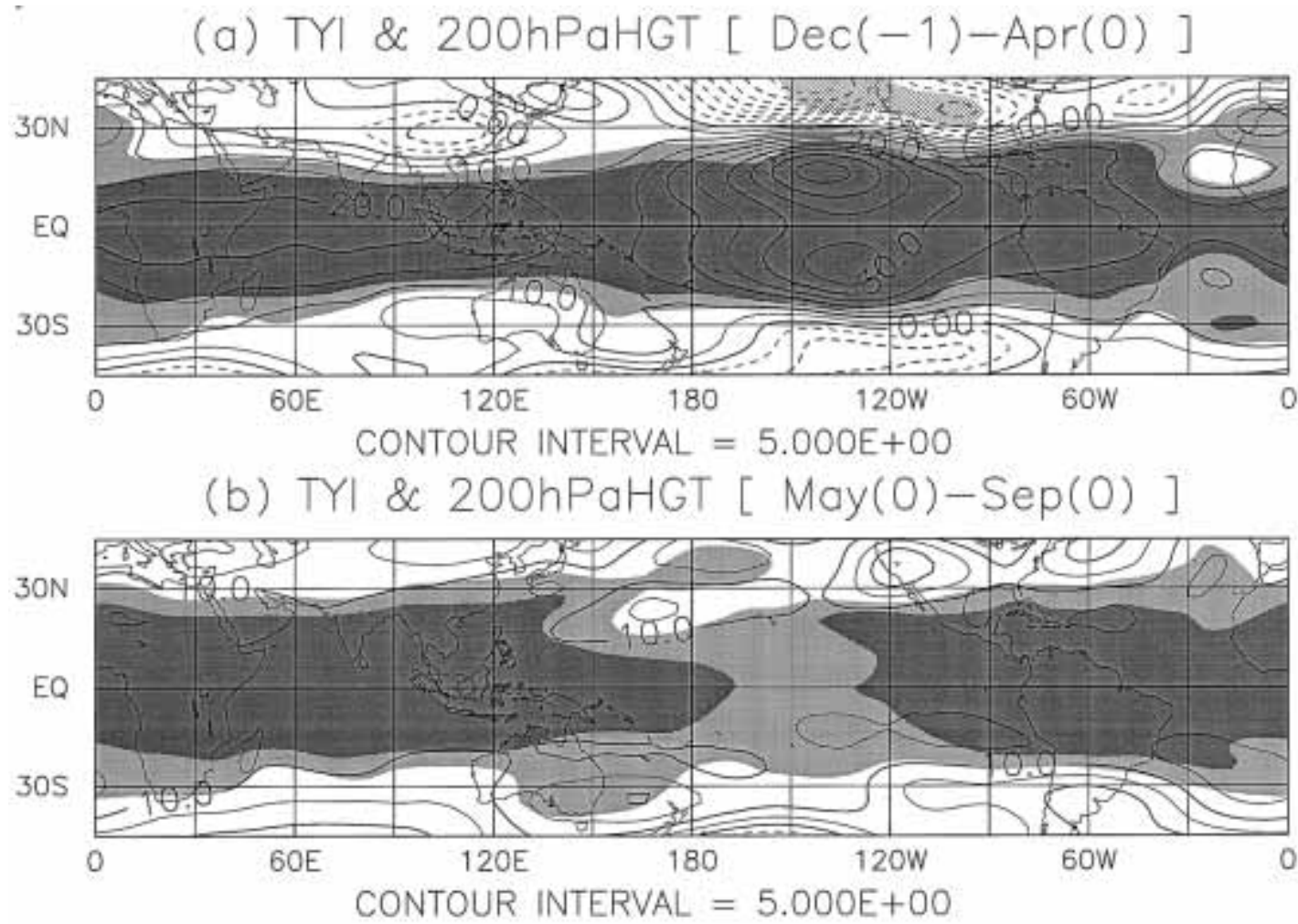

Fig. 5. Horizontal maps of $200 \mathrm{hPa}$ height anomalies regressed upon the TYI as indicated by the contours. The degrees of shading indicate the correlation coefficients between the TYI and $200 \mathrm{hPa}$ heights and denote the same values as in Fig. 3. The heights were averaged over (a) December(-1)-April(0) and (b) May(0)-September(0), i.e., before and after the spring persistence barrier of the ENSO. The contour interval is $5 \mathrm{~m}$.

as Yulaeva and Wallace (1994), and Wallace et al. (1998). Note that while there are areas of anomalies greater than $30 \mathrm{~m}$ over the tropical central Pacific, secondary peaks are found over the African Continent and the Indian Ocean near the equator, where the anomalies are greater than $20 \mathrm{~m}$.

After the spring persistence barrier (Fig. 5b), significant positive correlations remain dominant over the entire tropics. The Gill mode-like wave pattern shown in Fig. 5a is not found, and the $200 \mathrm{hPa}$ height anomalies are uniform, and slightly above $10 \mathrm{~m}$ in the tropics.

Figures $6 \mathrm{a}$ and $\mathrm{b}$ are the same as in Fig. 5, except for SST variations. Over the tropical central and eastern Pacific, including the NINO3 area, significant positive correlation coefficients are found (Fig. 6a). This correlation pattern is the same as that found in previous papers (e.g., Wallace et al. 1998). The maximum of regressed SST anomalies exceeds $1 \mathrm{~K}$ (tropical central Pacific). In contrast with Fig. 6a, few significant correlations are found over the tropical central and eastern Pacific, in Fig. 6b.

It has been demonstrated that positive SST anomalies usually appear in the Indian Ocean and the tropical North Atlantic, approximately 3 to 6 months after SST anomalies peak in the tropical Pacific (Klein et al. 1999). Correlation coefficients for the SST in the tropical Indian Ocean are above the $1 \%$ significance level in Figs. $6 a$ and b. Note that the tropical SST anomalies over the Indian Ocean are at most $0.2 \mathrm{~K}$, and much smaller than those over the eastern Pacific. Over the North Atlantic and the South China Sea, although the regressed anomalies are as small as those over the Indian Ocean, the correlation coefficients for SST are above the $1 \%$ significance level in Fig. $6 \mathrm{~b}$. 
(a) TYI \& SST [ $\operatorname{Dec}(-1)-\operatorname{Apr}(0)]$
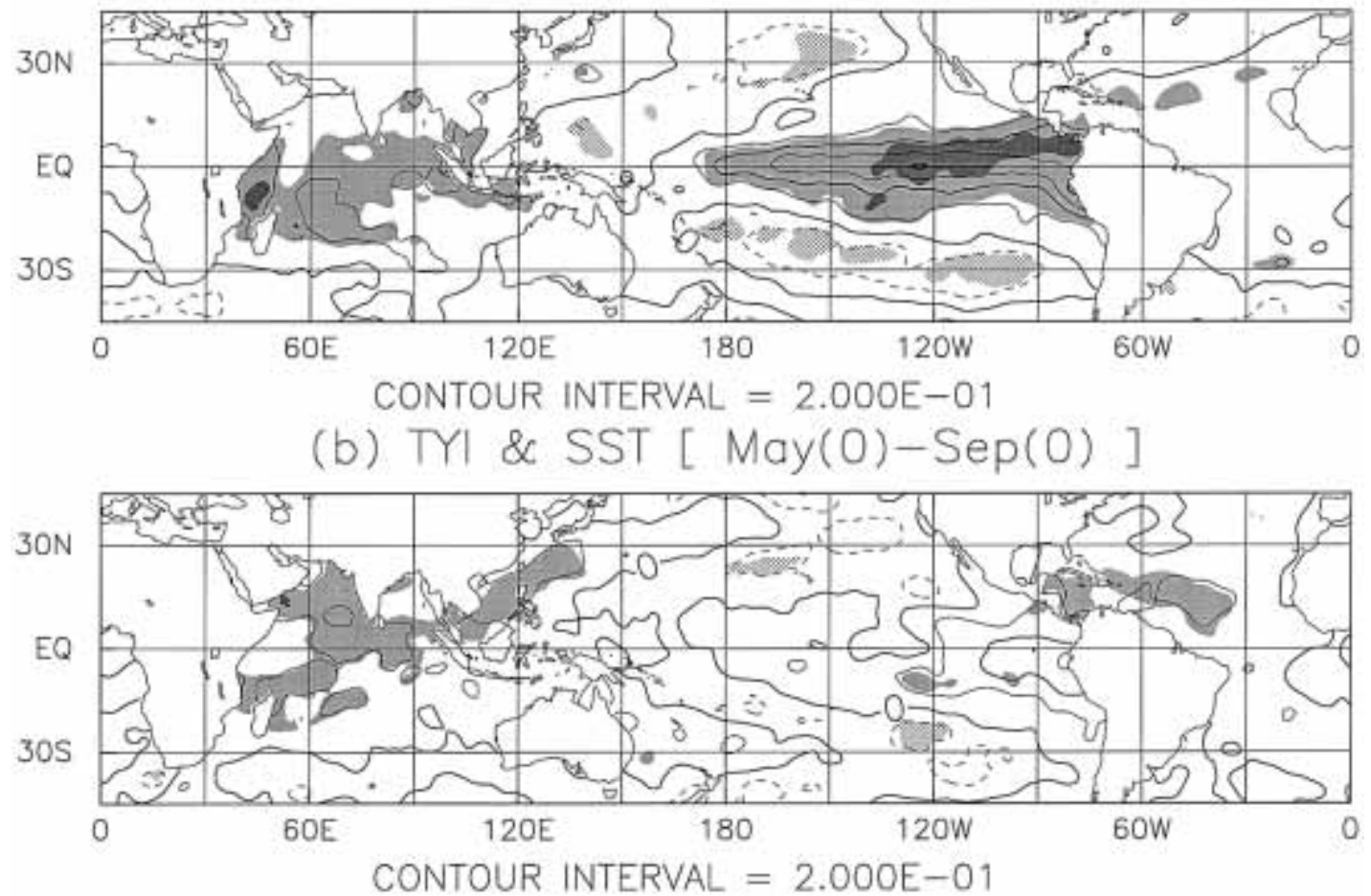

Fig. 6. The same as in Fig. 5, except that the SST is taken as the target variable, and the contour interval is $0.2 \mathrm{~K}$.

\subsection{Meridional and vertical structure}

Figure 5b exhibited a zonal symmetry of the $200 \mathrm{hPa}$ height variations in the tropics. Zonal symmetry is due to the inefficiency of the Coriolis effect in compensating the pressure gradients in low latitudes, and the nearly inviscid character of the time-mean, upper-tropospheric motions there (Schneider et al. 1997). This subsection describes the meridional and vertical structures of the persistence of zonally averaged tropical temperatures.

Figure 7 shows a latitude-time diagram of the zonal mean $200 \mathrm{hPa}$ height anomalies regressed on the TYI as indicated by the contours. The degrees of shading indicate the lagged correlation coefficients between the TYI (the reference variable) and zonal mean $200 \mathrm{hPa}$ heights (the target variable). Correlation coefficients for heights over the latitudes bounded by $20^{\circ} \mathrm{S}-20^{\circ} \mathrm{N}$ exceed the $1 \%$ significance level in November $(-1)$, and continue above the significance level until September(0). In particular, correlation coefficients for heights

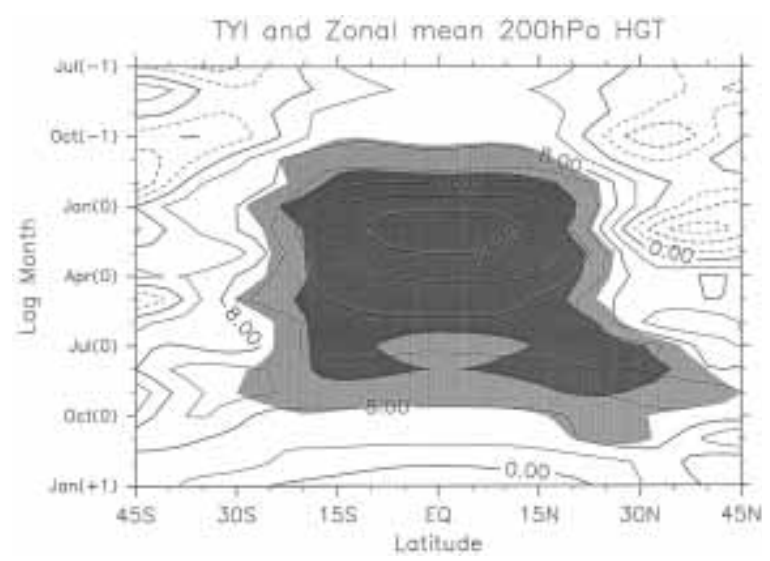

Fig. 7. Latitude-time diagram of zonal mean $200 \mathrm{hPa}$ height anomalies regressed on the TYI as indicated by the contours. The degrees of shading indicate the lagged correlation coefficients between the TYI (the reference variable) and zonal mean $200 \mathrm{hPa}$ height (the target variable) and zonal mean $200 \mathrm{hPa}$ height and have the same values as in Fig. 3. The vertical axis denotes the months of the target variables. The contour interval is $4 \mathrm{~m}$. 


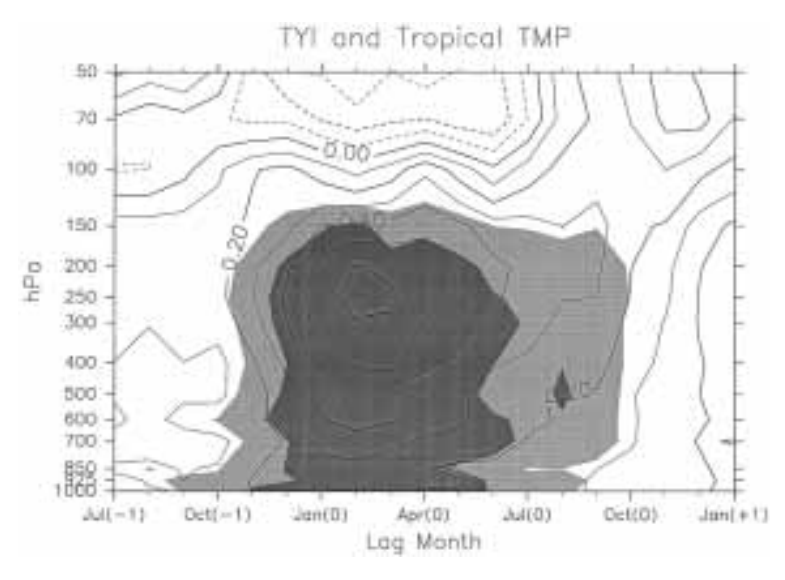

Fig. 8. Time-height diagram of the tropical temperature anomalies regressed on the TYI as indicated by the contours. The degrees of shading indicate the lagged correlation coefficients between the TYI and tropical temperatures with the same values as in Fig. 3. The horizontal axis denotes the months of the target variables. The temperatures were averaged zonally between $15^{\circ} \mathrm{S}$ and $15^{\circ} \mathrm{N}$. The contour interval is $0.1 \mathrm{~K}$.

over latitudes within $15^{\circ} \mathrm{S}-15^{\circ} \mathrm{N}$ are greater than 0.8 (dark shading).

Note that positive correlation coefficients are higher after $\operatorname{July}(0)$ in the subtropics than near the equator. Significant positive correlations are found for heights over the subtropical region, around $30^{\circ} \mathrm{N}$, during the summer in the Northern Hemisphere. This corresponds to the upper tropospheric subtropical anticyclones, such as the Tibetan High, which was verified in the horizontal maps (not shown).

The $200 \mathrm{hPa}$ height anomalies regressed upon the TYI over the latitudes within $15^{\circ} \mathrm{S}-$ $15^{\circ} \mathrm{N}$, increase rapidly between November $(-1)$ and February $(0)$, and then decrease slowly between February(0) and September(0), as was shown in Fig. 4.

The vertical structure of the anomalies is examined with the use of temperature data. Figure 8 shows a time-height diagram where the contours represent tropical temperature anomalies regressed upon the TYI, while the degrees of shading indicate lagged correlation coefficients between the TYI and tropical temperatures. The temperatures at each pressure level were averaged over the tropics, between $15^{\circ} \mathrm{S}$ and $15^{\circ} \mathrm{N}$. Reanalysis data are given at the levels of the pressure surfaces labeled on the vertical axis.

There are significant positive correlation coefficients over the period between November $(-1)$ and September $(0)$ at almost all levels below $150 \mathrm{hPa}$. This confirms that the variation of the $200 \mathrm{hPa}$ height reflects the temperature variation of the entire tropical troposphere. Interestingly, the correlations at all levels between $700 \mathrm{hPa}$ and $150 \mathrm{hPa}$ decrease below the significant level during September $(0)$ and $\operatorname{October}(0)$. The correlation coefficients for temperatures below $850 \mathrm{hPa}$ (light shading), exceed the $1 \%$ significance level on September $(-1)$, which is two months earlier than between $700 \mathrm{hPa}$ and $150 \mathrm{hPa}$.

For all months, the temperature anomalies regressed upon the TYI are larger in the upper troposphere $(0.4-0.6 \mathrm{~K})$ than in the lower troposphere $(0.2-0.3 \mathrm{~K})$. A maximum in the regressed anomalies (contours) is found at $250 \mathrm{hPa}$ in February(0), with a value of $0.6 \mathrm{~K}$. This indicates that the variations of $200 \mathrm{hPa}$ heights mainly reflect the variations in the middle and upper level tropospheric temperatures.

\section{Differences between the planetary boundary layer and the free troposphere}

The variation in the zonally averaged tropical temperature was presented in the previous section. This section describes longitudinal differences in tropical temperatures within the vertical structure.

Figures 9a and b display longitude-height diagrams of tropical temperature anomalies regressed on the TYI, before and after the spring persistence barrier of the ENSO, respectively. The temperatures were averaged between $15^{\circ} \mathrm{S}$ and $15^{\circ} \mathrm{N}$. In both Fig. 9a for December $(-1)-$ $\operatorname{April}(0)$, and Fig. 9b for $\operatorname{May}(0)-\operatorname{September}(0)$, marked differences are found in the correlation coefficients among the pressure levels.

High positive correlation coefficients of tropical temperatures vary zonally between the $1000 \mathrm{hPa}$ and $850 \mathrm{hPa}$ levels, which is nearly equivalent to the atmospheric planetary boundary layer. Significant correlations are found over tropical areas of the central and eastern Pacific, the Indian Ocean, and the American 
(a) M \& Tropical TMP [ Dec(-1)-Apr(0) ]

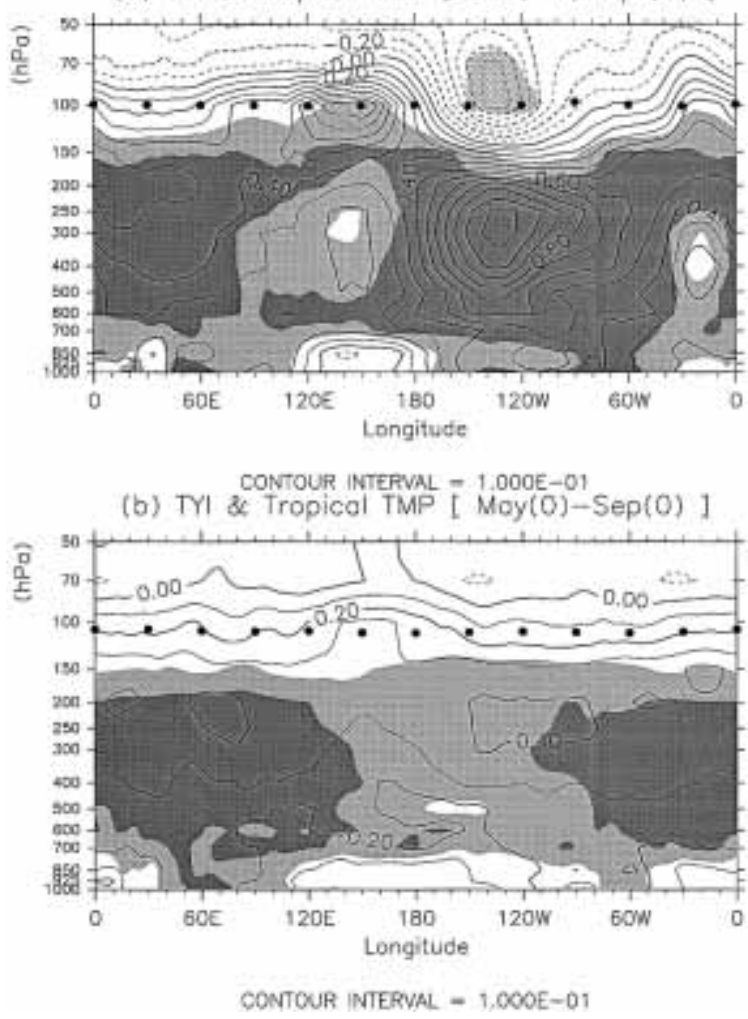

Fig. 9. Longitude-height diagrams of tropical temperature anomalies regressed on the TYI as indicated by the contours. The temperatures were averaged over (a) December $(-1)-\operatorname{April}(0)$ and (b) May(0)-September(0). The degrees of shading indicate the lagged correlation coefficients between the TYI and tropical temperatures with the same values as in Fig. 3. The temperatures were averaged between $15^{\circ} \mathrm{S}$ and $15^{\circ} \mathrm{N}$. The contour interval is $0.1 \mathrm{~K}$. Solid circles denote tropical $\left(15^{\circ} \mathrm{S}-\right.$ $15^{\circ} \mathrm{N}$ ) tropopause pressures averaged over 22 years for (a) December-April and (b) May-September.

Continent in Fig. 9a, and the Indian Ocean and the American Continent in Fig. 9b. The above areas well-correspond with the results in Figs. 6 for the SSTs. This result indicates that the temperatures in the tropical planetary boundary layer vary almost simultaneously with the underlying SSTs.

The tropical temperatures at the levels between $700 \mathrm{hPa}$ and $150 \mathrm{hPa}$ (the free tropo- sphere) demonstrate the zonal variations in both figures. Correlation coefficients are above the significance level at almost all longitudes. The wave pattern similar to a Gill-mode, centered in the Pacific, is found only in Fig. 9a. At the levels between $700 \mathrm{hPa}$ and $150 \mathrm{hPa}$, anomalies are large and significant over the central Pacific, while small and insignificant over two regions, the Atlantic and the Maritime Continent (the western Pacific and south eastern Asia). In contrast, anomalies near the tropopause show variations that are out of phase with the underlying free troposphere. This anomaly pattern appears to be the result of the response of tropical planetary waves, including Kelvin and Rossby waves (Gill 1980). Large positive anomalies greater than $1 \mathrm{~K}$ are seen over the central Pacific around $250 \mathrm{hPa}$ level. The level of maximum positive anomalies is found at $250-300 \mathrm{hPa}$ over the eastern $\mathrm{Pa}$ cific, while, in other areas, it is found at a somewhat higher level, near 150-200 hPa.

Thus, tropical temperature anomalies can be divided into those occurring in the planetary boundary layer $(1000 \mathrm{hPa}-850 \mathrm{hPa})$, and those in the free troposphere $(700 \mathrm{hPa}-150 \mathrm{hPa})$. The relationships between the TYI and tropical temperatures at the 1000-850 hPa levels and the $700-150 \mathrm{hPa}$ levels are shown in Figs. 10b and c, respectively. Here, the lagged correlation coefficients with the TYI, and anomalies regressed on the TYI, are indicated by the shading and contours, respectively. The top panel (Fig. 10a) is the same as in Figs. 10b and c, except for the SSTs.

In Figs. 10a and $\mathrm{b}$, positive correlation coefficients above the 1\% significance level are found over the central and eastern Pacific $\left(180^{\circ}-80^{\circ} \mathrm{W}\right)$, and the Indian Ocean $\left(45^{\circ}\right.$ $\left.110^{\circ} \mathrm{E}\right)$, for the periods from $\operatorname{July}(-1)$ to $\operatorname{April}(0)$ and from October(-1) to $\operatorname{August(0),}$ respectively. Over the Maritime Continent, correlation coefficients are significantly negative during September $(-1)$. Thus, it is shown that the tropical temperature anomalies at the $1000-850 \mathrm{hPa}$ levels over oceanic regions tend to almost simultaneously follow the underlying SST variations. On the other hand, in the upper tropical troposphere, from November $(-1)$ to September(0) (Fig. 10c), more zonally uniform, significant positive correlation coefficients are found. 
(a) TYI and Tropical SST

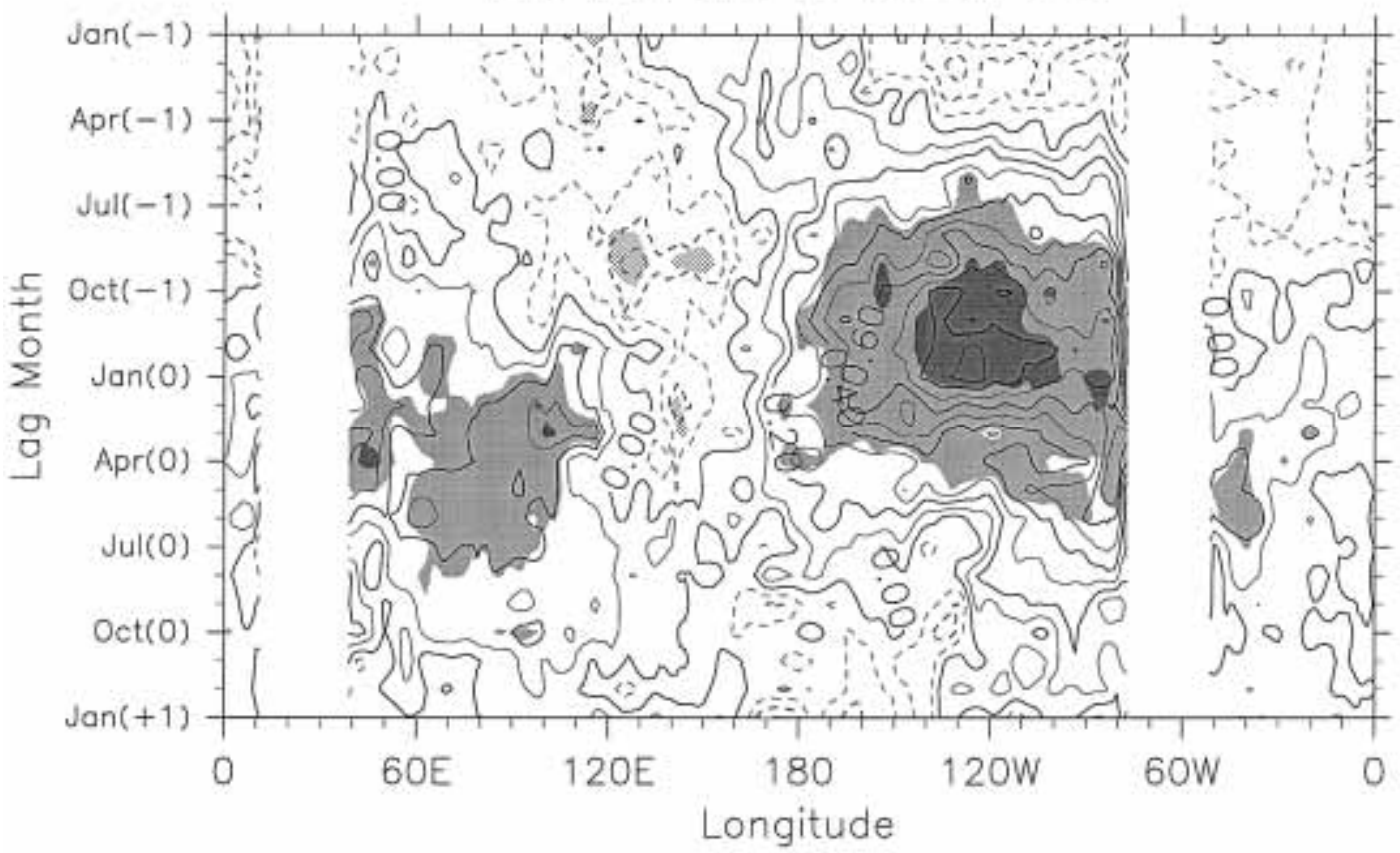

CONTOUR INTERVAL $=1.000 E-01$

(b) TYI and Tropical TMP(1000-850 hPa)

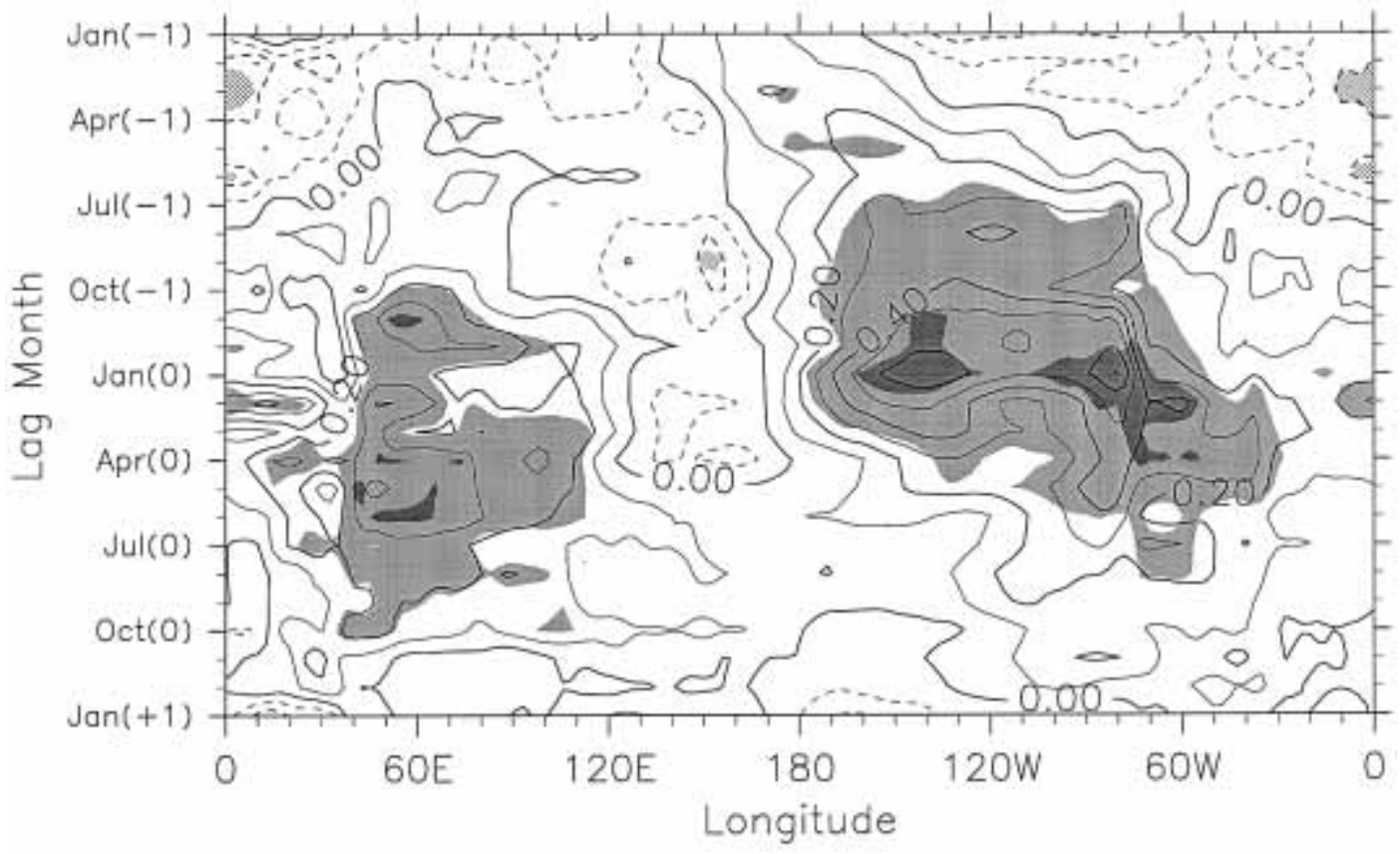

CONTOUR INTERVAL $=1.000 E-01$ 


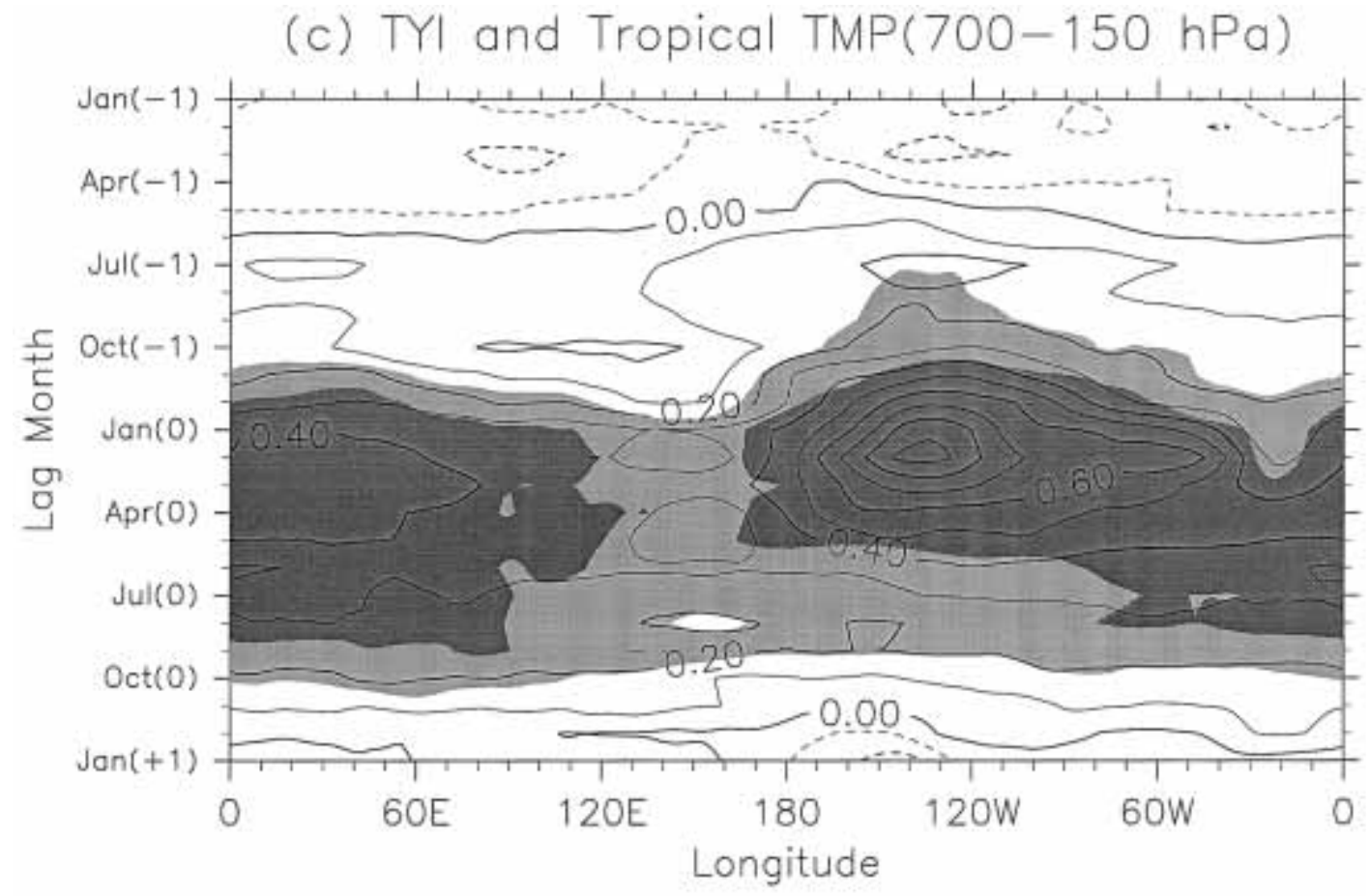

CONTOUR INTERVAL $=1.000 \mathrm{E}-01$

Fig. 10. Longitude-time diagrams of anomalies regressed upon the TYI as indicated by the contours. The degrees of shading indicate the lagged correlation coefficients between the TYI and target variables with the same values as in Fig. 3. Target variables are (a) the tropical SSTs, the temperatures (b) over the 1000-850 hPa levels, and (c) over the 700-150 hPa levels, which were averaged between $15^{\circ} \mathrm{S}$ and $15^{\circ} \mathrm{N}$. The contour interval is $0.1 \mathrm{~K}$.

Maximum anomalies of the SST and the lower-level temperature are detected during January $(0)$, around $125^{\circ} \mathrm{W}$ and $80^{\circ} \mathrm{W}$ with values of $1 \mathrm{~K}$ and $0.7 \mathrm{~K}$, respectively. A secondary maximum anomaly in the lower-level temperature is also found around $140^{\circ} \mathrm{W}$, with a value of $0.7 \mathrm{~K}$. Maximum anomalies of the upper-level temperature are seen during February $(0)$ around $140^{\circ} \mathrm{W}$ with a value of $0.9 \mathrm{~K}$. The longitude is near that of the secondary maximum low-level anomaly.

In addition, it is of interest that Fig. 10b exhibits significant temperature variations over the land surface such as the South American Continent $\left(80^{\circ}-40^{\circ} \mathrm{W}\right)$, where correlation coefficients are above the $1 \%$ significance level for the period between February(0) and June(0). The magnitudes of temperature anomalies over the South American Continent are about half those over the eastern Pacific. There is little significant correlation over the African Continent.

From August $(-1)$ to $\operatorname{October}(-1)$, upperlevel temperature variations associated with ENSO events are seen only over the central Pacific around $140^{\circ} \mathrm{W}$, and there is no zonal uniformity. This may be related to the weak response of the tropical $200 \mathrm{hPa}$ heights to SST anomalies in the fall, as pointed out by Kawamura et al. (1995) based on calculations of an atmospheric general circulation model, forced with observed SSTs.

Over the Indian and Atlantic Oceans, significant positive temperature anomalies in the lower levels of the troposphere precede those of SSTs by about one month. This leads to the speculation that the SST variations over ocean basins remote from the Pacific are induced by tropospheric temperatures. 


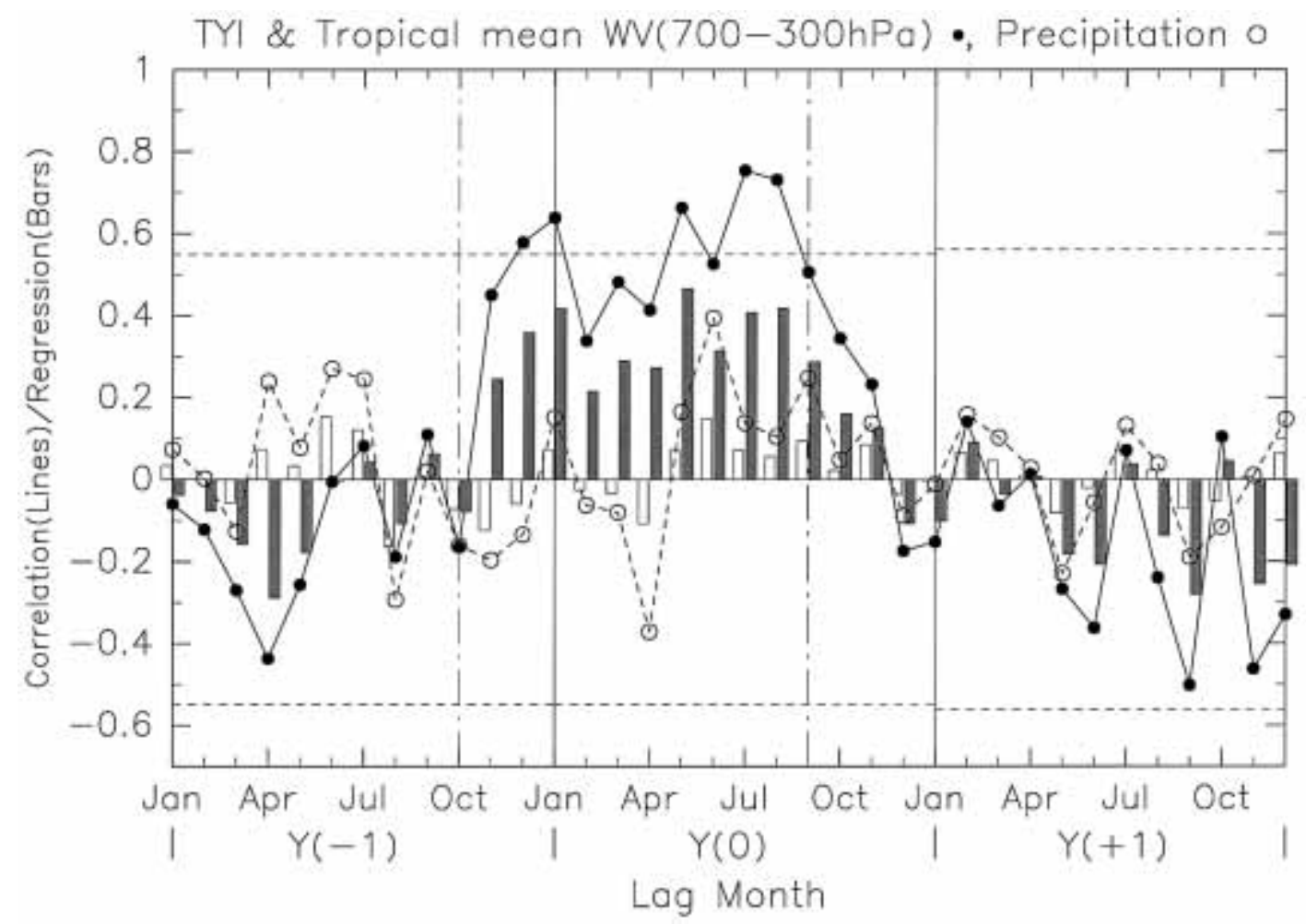

Fig. 11. The same as in Fig. 4, except that the mass of water vapor at 700-300 hPa (solid circles, hatched bars) and the precipitation rate (open circles, open bars) are taken as the target variables. The mass of water vapor and the precipitation rate were averaged zonally between $15^{\circ} \mathrm{S}$ and $15^{\circ} \mathrm{N}$ and between $16.25^{\circ} \mathrm{S}$ and $16.25^{\circ} \mathrm{N}$, respectively. Values of the anomalies of water vapor $\left(\mathrm{kg} \mathrm{m}^{-2}\right)$ and the precipitation rate $\left(\mathrm{mm} \mathrm{day}^{-1}\right)$ were multiplied by a factor of 2.0.

\section{Precipitation and water vapor variations}

This section describes variations in water vapor and precipitation, which may be closely connected with the variations in the tropical tropospheric temperatures, as shown in previous sections.

Lagged correlations are calculated between the TYI and the mean mass of tropical water vapor over the $700-300 \mathrm{hPa}$ levels; i.e., the total mass of water vapor in a unit area column of air that extends from the $700 \mathrm{hPa}$ surface to the $300 \mathrm{hPa}$ surface. Figure 11 is the same as in Fig. 4, except that the mass of water vapor (solid circles, hatched bars) is taken as the target variable. The mass of water vapor was averaged over the tropics between $15^{\circ} \mathrm{S}$ and $15^{\circ} \mathrm{N}$. High positive correlation coefficients are found during the period between November $(-1)$ and September(0), although values are slightly below the $1 \%$ significant level during a number of months. The anomalies rapidly increase during the period between November $(-1)\left[0.12 \mathrm{~kg} \mathrm{~m}^{-2}\right]$ and $\operatorname{January}(0)$ $\left[0.21 \mathrm{~kg} \mathrm{~m}^{-2}\right]$. Interestingly, the anomalies do not fall, but increase gradually over the period from February $(0)\left[0.11 \mathrm{~kg} \mathrm{~m}^{-2}\right]$ to $\operatorname{August}(0)$ $\left[0.21 \mathrm{~kg} \mathrm{~m}^{-2}\right.$ ], unlike those for the tropospheric temperatures shown in Fig. 4. This above normal mass of water vapor may contribute to the tropical tropospheric warming after the El Niño events through the modification of the radiative equilibrium. On the other hand, below normal water vapor may contribute to tropical tropospheric cooling after La Niña events, also through the modification of radiative equilibrium.

The longitudinal structure of water vapor is examined in Fig. 12. Figure 12 is the same as in Fig. 10, except that the mass of water vapor between the $700 \mathrm{hPa}$ and $300 \mathrm{hPa}$ levels is 


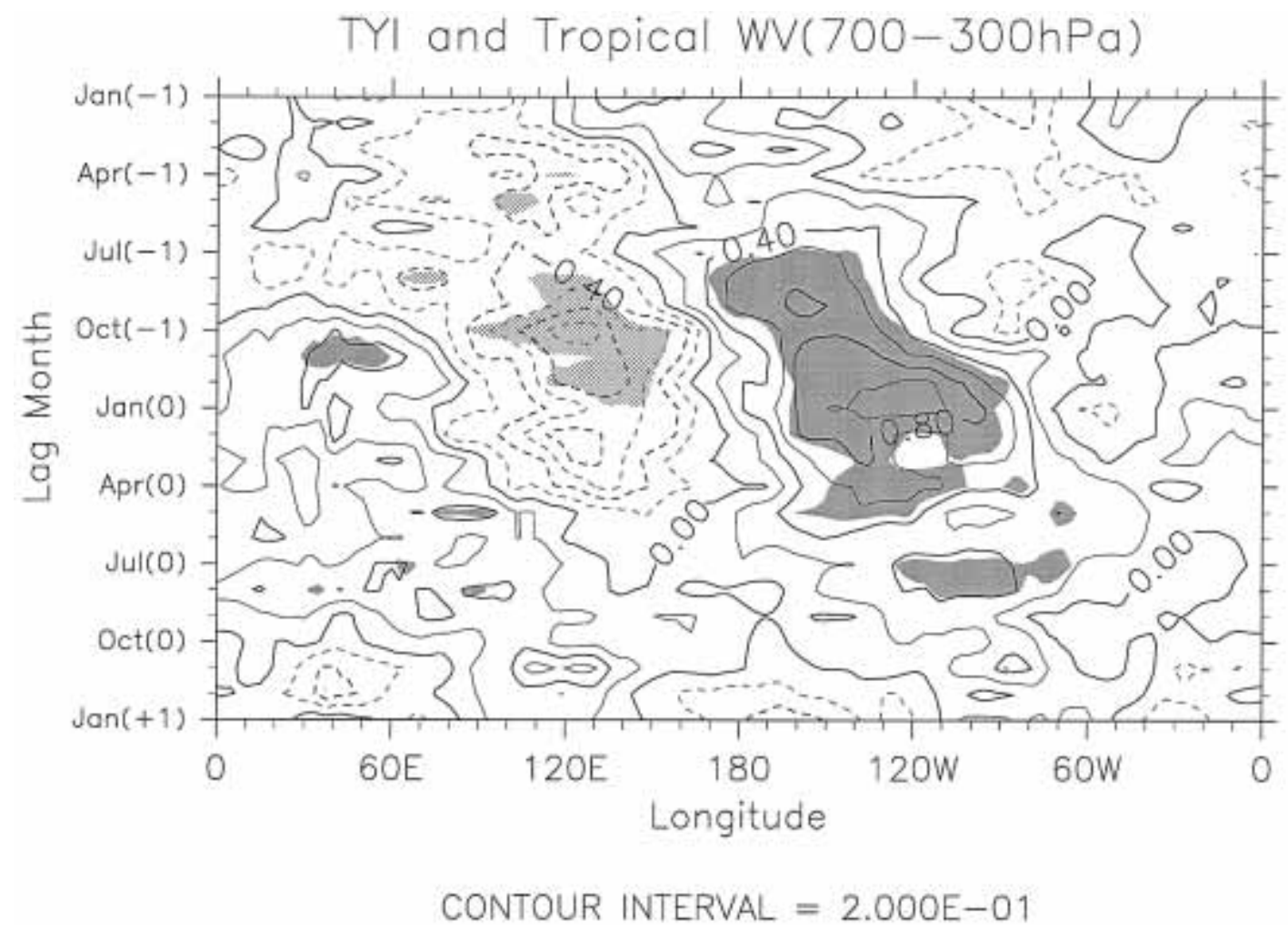

Fig. 12. The same as in Fig. 10, except that the mass of water vapor over the 700-300 hPa levels is taken as the target variable. The mass of water vapor was averaged between $15^{\circ} \mathrm{S}$ and $15^{\circ} \mathrm{N}$. The contour interval is $0.2 \mathrm{~kg} \mathrm{~m}^{-2}$.

taken as the target variable. The figure does not exhibit the zonal uniformity, being similar to Figs. 10a and b, rather than Fig. 10c. The correlation coefficients are significantly positive over the Pacific [August $(-1)-\operatorname{May}(0)$ ] and negative over the Maritime Continent [August $(-1)-\operatorname{December}(-1)]$. Significant positive anomalies are found at times over the Indian Ocean. Large positive anomalies are found over the central and eastern Pacific, while negative anomalies are dominant over the Maritime Continent during the ENSO events shown in Fig. 10a.

During $\operatorname{July}(0)$, positive correlation coefficients revive over the eastern Pacific $\left(120^{\circ}-\right.$ $70^{\circ} \mathrm{W}$ ), indicating that water vapor anomalies are sustained, even after the spring persistence barrier of the ENSO indices.

Figure 11 also shows the results where the tropical mean precipitation rate is used as the target variable. The precipitation rate was averaged over the tropics between $16.25^{\circ} \mathrm{S}$ and $16.25^{\circ} \mathrm{N}$. No significant correlation coefficient is found. These results indicate that the tropical tropospheric warming is not directly connected with the increase in the amount of tropical precipitation, nor is cooling related to the decrease in tropical precipitation.

To discuss this point in more detail, the horizontal structure of precipitation anomalies associated with the TYI is examined. Figure 13 is the same as in Figs. 5 and 6, except that the precipitation rate is taken as the target variable. During ENSO events, positive correlation coefficients are found over the central and eastern Pacific along the equator, while negative values occur over the Maritime Continent, and the South Pacific Convergence Zone (SPCZ).

Large precipitation anomalies, greater than $1.5 \mathrm{~mm} \mathrm{day}{ }^{-1}$, are concentrated over the equatorial central Pacific, which may be connected with the Gill mode-like wave pattern shown in Figs. 5a and 9a. They are offset, however, by negative anomalies over the Maritime Conti- 


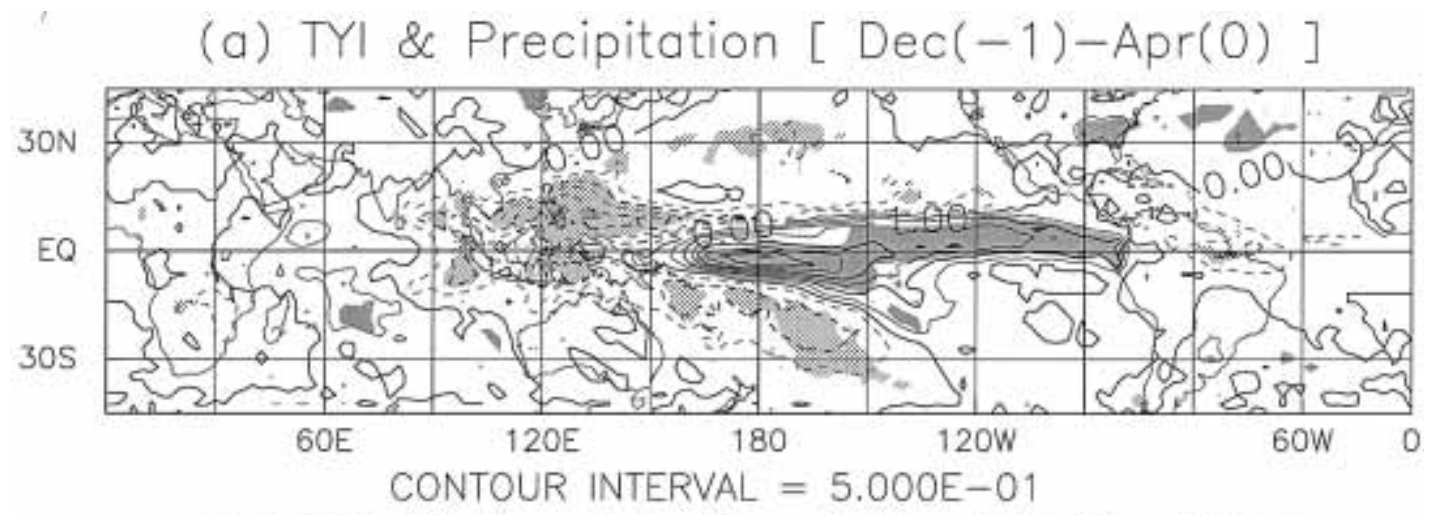

(b) $T Y \mid$ \& Precipitation [ May(O)-Sep(O) ]

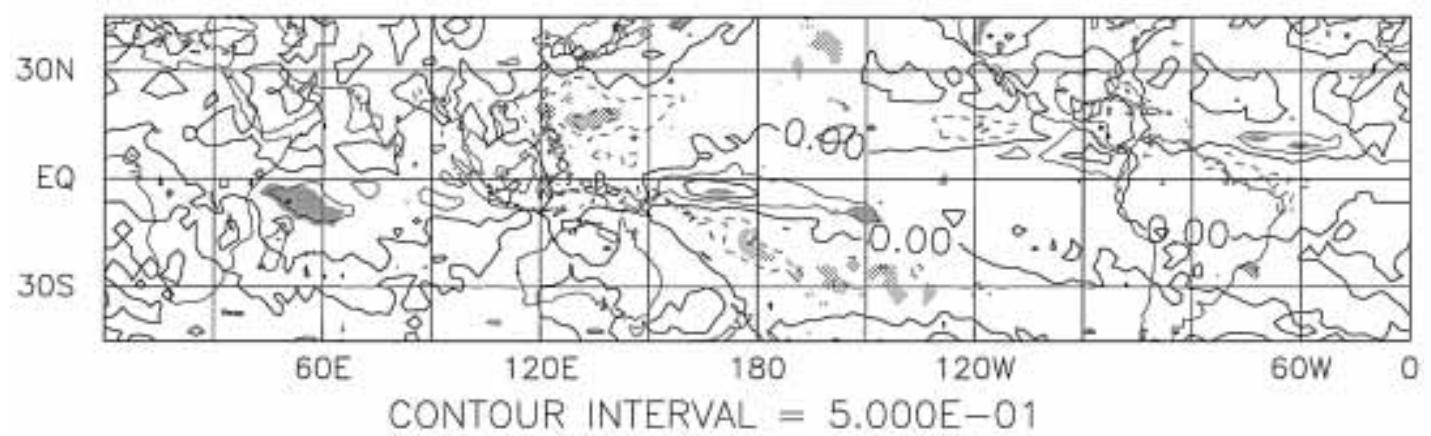

Fig. 13. The same as in Figs. 5 and 6, except that the precipitation rate is taken as the target variable. The contour interval is $0.5 \mathrm{~mm} \mathrm{day}^{-1}$.

nent and the SPCZ, and all of the tropical mean values are not correlated with the TYI (Fig. 11). This may suggest that the variations of the tropospheric temperature throughout the tropics are more sensitive to the concentrated diabatic heating over the Pacific along the equator, than the widespread precipitation anomalies over the Maritime Continent and the SPCZ.

On the other hand, after the decay of the ENSO event, there are few areas where the correlation coefficients exceed the significant level, in spite of the fact that significant SST anomalies are found over the Indian Ocean in Fig. 6b. Significant correlation coefficients are rarely found between the TYI, and the monthly precipitation fields, after May(0) (not shown). This result is consistent with Webster et al. (1998), which indicated that the relationship between the SST and the outgoing longwave radiation appeared weak in the Indian Ocean, although in the Pacific Ocean, the convection height generally increased with increasing SST. Over the Indian Ocean, the strength of convective activity is not strongly related with SST variations.

\section{Conclusions}

Using the NCEP-NCAR reanalysis data from 1979 through 2000, it was shown that the tropical tropospheric mean temperature tended to persist from autumn to the following autumn, and that there was a persistence barrier of the tropical tropospheric mean temperature in the boreal autumn. This feature lagged by 4 months, behind the spring persistence barrier of the ENSO indices. Based upon this persistence barrier of tropical temperature, another definition of the climatic year was proposed for the tropical tropospheric temperature, namely, the year starting with the boreal autumn. Thus, the Tropical Year Index (TYI) was defined as the tropical $\left(15^{\circ} \mathrm{S}-15^{\circ} \mathrm{N}\right)$ zonal mean $200 \mathrm{hPa}$ height, averaged over the period between October of the previous year, and September of the reference year.

A nearly zonal variation of temperature was 
seen over the period between November $(-1)$ and September $(0)$ in the free troposphere $(700 \mathrm{hPa}-150 \mathrm{hPa})$ within the latitudes between $20^{\circ} \mathrm{S}$ and $20^{\circ} \mathrm{N}$. On the other hand, the tropical temperatures within the planetary boundary layer $(1000 \mathrm{hPa}-850 \mathrm{hPa})$ almost simultaneously responded to the SSTs below the layer.

The NINO3 SST anomalies, and the tropical zonal mean $200 \mathrm{hPa}$ height anomalies increased during July $(-1)-\operatorname{December}(-1)$ and November $(-1)-F e b r u a r y(0)$, and then decreased during December(-1)-April(0) and February(0)-September(0), respectively. This result did not indicate that the variations of the tropical temperature associated with the TYI were simply lagged behind those of the tropical eastern Pacific SST. The temperature anomalies were the largest in February(0) over the central Pacific, around $130^{\circ} \mathrm{W}$ at the $250 \mathrm{hPa}$ level.

Some systematic variations were found over ocean basins remote from the Pacific, in particular, the Indian Ocean after the spring persistence barrier. The SSTs of the Indian Ocean $\left(45^{\circ}-110^{\circ} \mathrm{E}\right)$ were above normal between October $(-1)$ and August(0) when the TYI was above normal. On the other hand, the SSTs were below normal between $\operatorname{October}(-1)$ and August $(0)$ when the TYI was below normal. However, the magnitude of the SST anomalies over the tropical Indian Ocean $(\sim 0.2 \mathrm{~K})$ was much smaller than that of the tropical eastern Pacific Ocean $(\sim 1.0 \mathrm{~K})$. Associated precipitation anomalies were not evident over the tropical Indian Ocean.

The tropical tropospheric warming (or cooling) was not directly connected with the increase (or decrease) in the amount of the precipitation accumulated over the entire tropics. Large precipitation anomalies, however, were found over the equatorial central Pacific during the mature ENSO. Significant tropical precipitation anomalies were not found after the decay of the ENSO event.

A close relationship between temperature, and the mass of water vapor, was verified at the 700-300 hPa levels. In addition, the anomalies of the tropical mean mass of water vapor over the $700-300 \mathrm{hPa}$ levels increased gradually from $\operatorname{February}(0)$ to $\operatorname{August}(0)$, particularly over the eastern Pacific, unlike the tropo- spheric temperatures. This may be the mechanism responsible for the tropical tropospheric warming after the decay of ENSO events.

\section{Acknowledgments}

The authors acknowledge valuable discussions with Professor Tatsuya Iwashima and Professor Hideji Kida. The authors thank Dr. Ryuichi Kawamura and anonymous reviewers for valuable comments. The GFD-DENNOU Library was used for drawing figures, and also for numerical calculations.

\section{References}

Angell, J.K., 1981: Comparison of variations in atmospheric quantities with sea surface temperature variations in the equatorial eastern Pacific. Mon. Wea. Rev., 109, 230-243.

Basist, A.N. and M. Chelliah, 1997: Comparison of tropospheric temperatures derived from NCEP operational analysis, and the Microwave Sounding Unit. Bull. Amer. Meteor. Soc., 78, 1431-1447.

Blankenship, C.B. and T.T. Wilheit, 2001: SSM/T-2 measurements of regional changes in threedimensional water vapor fields during ENSO events. J. Geophys. Res., 106, 5239-5254.

Chelliah, M. and C.F. Ropelewski, 2000: Reanalysesbased tropospheric temperature estimates: Uncertainties in the context of global climate change detection. J. Climate, 13, 3187-3205.

Gill, A.E., 1980: Some simple solutions for heatinduced tropical circulation. Quart. J. Roy. Meteor. Soc., 106, 447-462.

Harrison, D.E. and N.K. Larkin, 1998: El Niñosouthern oscillation sea surface temperature and wind anomalies, 1946-1993. Rev. Geophys., 36, 353-399.

Horel, J.D. and J.M. Wallace, 1981: Planetary-scale atmospheric phenomena associated with the Southern Oscillation. Mon. Wea. Rev., 109, 813-829.

Houghton, J.T., Y. Ding, D.J. Griggs, M. Noguer, P.J. van der Linden, X. Dai, K. Maskell, and C.A. Johnson, 2001: Climate change 2001, The scientific basis. Cambridge University Press, 881pp.

Hurrell, J.W. and K.E. Trenberth, 1999: Global sea surface temperature analyses: Multiple problems and their implications for climate analysis, modeling, and reanalysis. Bull. Amer. Meteor. Soc., 80, 2661-2678.

Kalnay, E., M. Kanamitsu, R. Kistler, W. Collins, D. Deaven, L. Gandin, M. Iredell, S. Saha, G. White, J. Woollen, Y. Zhu, M. Chelliah, W. 
Ebisuzaki, W. Higgins, J. Janowiak, K.C. Mo, C. Ropelewski, J. Wang, A. Leetmaa, R. Reynolds, R. Jenne, and D. Joseph, 1996: The NCEP/NCAR 40-year reanalysis project. Bull. Amer. Meteor. Soc., 77, 437-471.

Kawamura, R., M. Sugi, and N. Sato, 1995: Interdecadal and interannual variability in the northern extratropical circulation simulated with the JMA global model. Part II: Summertime leading mode. J. Climate, 8, 3020-3027.

Klein, S.A., B.J. Soden, and N.-C. Lau, 1999: Remote sea surface temperature variations during ENSO: Evidence for a tropical atmospheric bridge. J. Climate, 12, 917-932.

Newell, R.E. and B.C. Weare, 1976: Ocean temperatures and large scale atmospheric variations. Nature, 262, 40-41.

and $\mathrm{Z}$. Wu, 1992: The interrelationship between temperature changes in the free atmosphere and sea surface temperature changes. J. Geophys. Res., 97, 3693-3709.

Nitta, T. and S. Yamada, 1989: Recent warming of tropical sea surface temperature and its relationship to the Northern Hemisphere circulation. J. Meteor. Soc. Japan, 67, 375-382.

Pan, Y.H. and A.H. Oort, 1983: Global climate variations connected with sea surface temperature anomalies in the eastern equatorial Pacific ocean for the 1958-73 period. Mon. Wea. Rev., 111, 1244-1258.

Peixoto, J.P. and A.H. Oort, 1992: Physics of Climate. American Institute of Physics, 520pp.

Rasmusson, E.M. and T.H. Carpenter, 1982: Variations in tropical sea surface temperature and surface wind fields associated with the Southern Oscillation/El Niño. Mon. Wea. Rev., 110, 354-384.

Schneider, E.K., Z. Zhu, B.S. Giese, B. Huang, B.P. Kirtman, J. Shukla, and J.A. Carton, 1997: Annual cycle and ENSO in a coupled oceanatmosphere general circulation model. Mon. Wea. Rev., 125, 680-702.

Sun, D.Z. and A.H. Oort, 1995: Humiditytemperature relationships in the tropical troposphere. J. Climate, 8, 1974-1987.

Torrence, C. and P.J. Webster, 1998: The annual cycle of persistence in the El Niño/Southern
Oscillation. Quart. J. Roy. Meteor. Soc., 124, 1985-2004.

Trenberth, K.E., 1990: Recent observed interdecadal climate change in the Northern Hemisphere. Bull. Amer. Meteor. Soc., 71, 988-993.

and C.J. Guillemot, 1998: Evaluation of the atmospheric moisture and hydrological cycle in the NCEP/NCAR reanalyses. Clim. Dyn., 14, $213-231$.

and D.J. Shea, 1987: On the evolution of the Southern Oscillation. Mon. Wea. Rev., 115, 3078-3096.

von Storch, H. and F.W. Zwiers, 1999: Statistical analysis in climate research. Cambridge University Press, 484pp.

Wallace, J.M., E.M. Rasmusson, T.P. Mitchell, V.E. Kousky, E.S. Sarachik, and H. von Storch, 1998: On the structure and evolution of ENSOrelated climate variability in the tropical $\mathrm{Pa}-$ cific: Lessons from TOGA. J. Geophys. Res., 103, 14241-14259.

Webster, P.J., V.O. Magaña, T.N. Palmer, J. Shukla, R.A. Tomas, M. Yanai, and T. Yasunari, 1998: Monsoons: Processes, predictability, and the prospects for prediction. J. Geophys. Res., 103, 14451-14510. and S. Yang, 1992: Monsoon and ENSO: Selectively interactive systems. Quart. J. Roy. Meteor. Soc., 118, 877-926.

Wright, P.B., 1985: The Southern Oscillation: An ocean-atmosphere feedback system? Bull. Amer. Meteor. Soc., 66, 398-412.

Xie, P. and P.A. Arkin, 1997: A 17-year monthly analysis based on gauge observations, satellite estimates and numerical model outputs. Bull. Amer. Meteor. Soc., 78, 2539-2558.

Yasunari, T., 1991: The monsoon year-A new concept of the climatic year in the tropics. Bull. Amer. Meteor. Soc., 72, 1331-1338.

- and Y. Seki, 1992: Role of the Asian monsoon on the interannual variability of the global climate system. J. Meteor. Soc. Japan, 70, 177189.

Yulaeva, E. and J.M. Wallace, 1994: The signature of ENSO in global temperature and precipitation fields derived from the microwave sounding unit. J. Climate, 7, 1719-1736. 